Научноисследовательский институт ревматологии им. В.А. Насоновой

Проблема инфекций

нижних дыхательных путей в ревматологии: актуальность и пути решения

\author{
Б.С. Белов, д.м.н., Д.В. Буханова, Г.М. Тарасова, к.м.н., Н.В. Муравьева, к.м.н.
}

Адрес для переписки: Борис Сергеевич Белов, belovbor@yandex.ru

Для цитирования: Белов Б.С., Буханова Д.В., Тарасова Г.М., Муравьева Н.В. Проблема инфекций нижних дыхательных путей в ревматологии: актуальность и пути решения // Эффективная фармакотерапия. 2020. Т. 16. № 6. С. 58-66.

DOI 10.33978/2307-3586-2020-16-6-58-66

Инфекции нижних дыхательных путей превалируют среди больных иммуновоспалительными ревматическими заболеваниями (ИВРЗ). Наиболее реальным возбудителем пневмонии как в общей популяиии, так и в популяции ИВРЗ по-прежнему считается пневмококк

(Streptococcus pneumoniae).

В статье приведены частота и факторы риска развития пневмонии при разных ИВРЗ. Представлены основные клинические характеристики, подходы к терапии и профилактике патологии в рамках пневмоиистной и изитомегаловирусной инфекиий. Подчеркнута значимость вакцинопрофилактики гриппа и пневмококковой инфекции у пациентов с ИВРЗ.

Ключевые слова: ревматические заболевания, инбекиии нижних дыхательных путей, пневмония, клинические проявления, лечение, профилактика
ДИ 4,0-6,0)), системной склеродермией (ОШ 4,2 (95\% ДИ 3,8-4,7)), синдромом Шегрена (ОШ 3,2 (95\% ДИ 2,9-3,5)), анкилозирующим спондилитом (ОШ 1,96 (95\% ДИ $1,07-3,30))$ [7].

У больных РА частота развития пневмонии составляет 2,4-8,3\% случаев, или 5,9-17,0 на 1 тыс. пациенто-лет, летальность от таковой - 8-22\% случаев, среди больных ИВР3 - 11-22\% [3, 4, 6, 8-10].

Этиология пневмонии непосредственно связана с микрофлорой, которая колонизирует слизистые оболочки верхних отделов дыхательных путей. Однако развитие воспалительной реакции способны вызвать лишь микроорганизмы с повышенной вирулентностью. В роли наиболее значимого возбудителя пневмонии в общей популяции по-прежнему выступает Streptococcus pneumoniae. Данный возбудитель наряду с Legionella spp., Staphylococcus aureus и Klebsiella pneumoniae признан этиологическим агентом внебольничной пневмонии, при которой летальность наиболее высока [11].

Примечательно, что среди пациентов со сниженным иммунитетом степень риска развития ИНДП неодинакова. Это объясняется рядом факторов, наиболее важными из которых считаются нейтропения, аспирация, тип и выраженность иммунологических расстройств, 
а также эпидемиологическая ситуация в регионе.

Анализ результатов наблюдения, проведенного F. Wolfe и соавт., свидетельствует, что за три года из 16788 пациентов с РА госпитализировано по поводу пневмонии 644 [9]. Общее количество госпитализаций - 749. Частота новых случаев развития пневмонии составила 17,0 на 1 тыс. пациенто-лет, при этом 19,2 на 1 тыс. пациенто-лет среди мужчин и 17,3 на 1 тыс. пациенто-лет среди женщин. У лиц в возрасте от 75 до 84 лет частота развития пневмонии была максимальной - 21,0 на 1 тыс. пациентолет. В качестве прогностических факторов развития заболевания фигурировали увеличение возраста пациентов на десять лет (относительный риск (ОР) 1,3 (95\% ДИ 1,3-1,4)), курение (ОР 1,3 (95\% ДИ $1,1-1,5))$, наличие сахарного диабета (ОР 2,0 (95\% ДИ 1,6-2,5)), перенесенный инфаркт миокарда (OP 2,1 (95\% ДИ 1,7-2,6)), предшествующие заболевания легких (OP 3,8 (95\% ДИ 3,2-4,4)). Риск развития пневмонии также повышался с длительностью РА на каждые десять лет (ОР 1,1 (95\% ДИ $1,0-1,2))$ и при назначении нового базисного противовоспалительного препарата (БПВП) или генно-инженерного биологического препарата (ГИБП) (ОР 1,1 (95\% ДИ $1,1-1,2))$. Увеличение на один балл оценки здоровья по HAQ ассоциировалось с возрастанием ОР до 2,0 (95\% ДИ 1,8-2,2). Ковариантный анализ показал, что назначение глюкокортикостероидов (ГКС) увеличивало риск развития пневмонии (OP 1,7 (95\% ДИ 1,5-2,1)). При этом последний во многом зависел от дозы препаратов. В частности, при суточной дозе ГКС $\leq 5$ мг OР составил 1,4 (95\% ДИ 1,11,6), 5-10 мг - 2,1 (95\% ДИ 1,7$2,7), \geq 10$ мг - 2,3 (95\% ДИ 1,6-3,2). Применение лефлуномида повышало риск до 1,3 (95\% ДИ 1,0-1,5), в то время как назначение сульфасалазина снижало его до 0,7 (95\% ДИ 0,4-1,0). Многофакторный анализ подтвердил значимость в развитии пневмонии у больных PA таких факторов, как возраст (OP 1,3$)$, наличие в анамнезе заболевания легких (ОР 2,9) и сахарного диабета (OP 1,5), применение ГКС (ОР 1,7), значение HAQ (OP 1,5) (p<0,001 во всех вышеприведенных случаях), количество БПВП и ГИБП (ОР 1,1; $\mathrm{p}=0,02)$ [12].

В исследовании, выполненном в Научно-исследовательском институте ревматологии им. B.A. Насоновой, у пациентов с PA выявлены такие факторы риска развития пневмонии, как высокая активность воспалительного процесса (ОШ 15,5 (95\% ДИ 5,3-45,1); $\mathrm{p}<0,001)$, наличие хронических заболеваний легких (ОШ 7,4 (95\% ДИ $1,4-39,9) ; p=0,01)$, отсутствие приема БПВП (ОШ 5,6 (95\% ДИ $2,3-14,1) ; \mathrm{p}<0,001)$ и применение ГКС в качестве монотерапии (ОШ 6,4 (95\% ДИ 1,8-23,1); $\mathrm{p}=0,005)$. Следует отметить, что при сочетании первого и третьего факторов риск развития пневмонии увеличивался до 19,3 [13]. Влияние приема БПВП на частоту развития ИНДП у больных РА изучали Р. Coyne и соавт. [14]. В исследование были включены 1522 пациента. Наблюдение за ними проводилось в одной поликлинике в течение календарного года. Частота ИНДП, которые потребовали госпитализации, составила 2,3\%, при лечении метотрексатом (MT) - 2,8\% $(\mathrm{p}=0,78)$. Логистический моновариантный регрессионный анализ выявил следующие значимые факторы риска развития ИНДП: пожилой возраст $(\mathrm{p}=0,013)$, мужской пол $(\mathrm{p}=0,022)$, применение ГКС ( $\mathrm{p}=0,041)$, отсутствие лечения БПВП ( $\mathrm{p}=0,019)$. Достоверных данных, свидетельствующих об ассоциации курения, назначения МТ или иных БПВП с частотой госпитализаций или смертей от инфекций органов дыхания, авторами не получено. По данным ретроспективного когортного исследования, выполненного в клинике Мейо, у больных PA с интерстициальным поражением легких частота инфекционной пневмонии достигала 3,9 на
100 пациенто-лет. Встречаемость инфекционных осложнений при организованной интерстициальной пневмонии была значимо выше, чем при обычной интерстициальной или неспецифической интерстициальной пневмонии, - 27,1 против 7,7 и 5,5 на 100 пациенто-лет $(p<0,001)$ [15].

Активное внедрение ГИБП в клиническую практику существенно повысило значимость проблемы развития пневмонии и других коморбидных инфекций при ИВРЗ [16].

Среди больных РА, включенных в германский регистр RABBIT, развитие ИНДП значимо чаще наблюдали при лечении инфликсимабом (ИНФ) (ОР 4,62 (95\% ДИ $1,4-9,5)$ ) и этанерцептом (ОР 2,81 $(95 \%$ ДИ 1,2-7,4)), чем при использовании традиционных БПВП [17]. В исследовании C. Salliot и соавт. среди получавших ингибиторы фактора некроза опухоли альфа (иФНО-альфа) инфекции зафиксированы в $34,5 \%$ случаев, тяжелые - в 17,0\% [18]. При сравнении с периодом до начала терапии ГИБП относительный риск развития серьезных коморбидных инфекций на фоне применения иФНО-альфа возрос в 3,1 раза. Самыми частыми были инфекции верхних и нижних дыхательных путей - 35,6 и 21,4\% случаев соответственно. На долю ИНДП приходилось 19,1\% из 47 случаев серьезных коморбидных инфекций. При сопоставлении трех препаратов из группы иФНО-альфа максимальное число инфекций (включая ИНДП) наблюдали при лечении ИНФ. С помощью мультифакториального анализа определены основные факторы риска развития коморбидных инфекций при использовании иФНО-альфа: оперативное вмешательство на суставах (OP 2,07 (95\% ДИ 1,43$2,98) ; \mathrm{p}<0,001)$ и суммарная доза ГКС (ОР 1,28 (95\% ДИ 1,04-1,59); $\mathrm{p}=0,02)$.

Согласно данным испанского регистра BIOBADASER, при лечении иФНО-альфа больных РА пневмонии были наиболее значимыми инфекционными осложнениями 
в отношении таких показателей, как морбидность и смертность. Таковые развивались в $11 \%$ случаев [19].

Согласно данным семилетнего наблюдения за 20814 больными РА, проведенного M. Lane и соавт., частота серьезных коморбидных инфекций, потребовавших госпитализации, составила 7\%. К значимым факторам риска развития тяжелых коморбидных инфекций были отнесены применение ГКС (OP 2,14 (95\% ДИ 1,88-2,43)) или иФНО-альфа (ОР 1,24 (95\% ДИ 1,02-1,50)). Наиболее частой вне зависимости от вида применяемого лечения была пневмония [20].

Исследование, посвященное изучению безопасности ритуксимаба (РТM) у 3194 пациентов с РА (включая 627 больных с длительностью терапии более пяти лет), продемонстрировало, что частота развития серьезных коморбидных инфекций достигла 3,94 на 100 пациенто-лет. При этом пневмония была наиболее частым серьезным инфекционным осложнением (2\%) [21].

Японские исследователи установили, что интенсивное внедрение в клиническую практику ингибитора интерлейкина 6 тоцилизумаба (ТЦЗ) повлекло за собой значимое увеличение числа серьезных ИНДП. Среди получавших ТЦЗ отмечено троекратное повышение частоты развития серьезных респираторных инфекций по сравнению с контрольной группой $-1,77$ и 0,53 на 100 пациенто-лет соответственно. При стандартизации выборок по полу и возрасту в группе ТЦЗ зафиксировано увеличение риска возникновения серьезных ИНДП в 3,64 раза (95\% ДИ 2,56-5,01) [22]. При формировании антибактериальной защиты макроорганизма особая роль отводится интерлейкину 6. С одной стороны, являясь эндогенным пирогеном, он инициирует повышение температуры тела, с другой - стимулирует продукцию белков острой фазы. Вследствие этого при лечении ТЦЗ больных РА клинические (лихорадка, слабость) и лабораторные (повышение скорости оседания эритроцитов и уровня С-реактивного белка) показатели инфекционного процесса могут быть стертыми или отсутствовать. Следовательно, необходимо сохранять высокую степень настороженности с целью раннего выявления инфекционных осложнений.

В качестве казуистики описаны два случая тяжелой пневмонии с минимальными клиническими проявлениями вначале и развитием шокового состояния в течение первых суток терапии ТЦЗ [23]. У больных системной красной волчанкой пневмония развивается достаточно часто (до $36 \%$ ) и является одной из наиболее значимых причин летального исхода. Ведущим этиологическим фактором пневмонии при системной красной волчанке является St. pneumoniae. В ретроспективном исследовании, выполненном в Дании, установлено, что частота инвазивных пневмококковых инфекций, включая пневмонию, среди больных системной красной волчанкой в 13 раз превышала таковую в популяции (210,0 и 15,6 на 10 тыс. пациентолет). По мнению авторов, данное обстоятельство является весомым аргументом в пользу вакцинации против пневмококковой инфекции всех пациентов с системной красной волчанкой [24].

Согласно данным R. Narata и соавт., частота внебольничной пневмонии у больных системной красной волчанкой составила $10,3 \%$ [25]. Средний возраст пациентов - 38,0 $\pm 11,5$ года, средняя продолжительность заболевания к моменту развития пневмонии $35,0 \pm 54,5$ месяца. Более чем в половине случаев $(58,9 \%)$ пневмония была зафиксирована на первом году заболевания, в 11 из них развитие пневмонии совпало с дебютом системной красной волчанки, в 22 - средняя продолжительность болезни составила $4,5 \pm 3,6$ месяца. Ведущими клиническими симптомами были фебрильная лихорадка $(83,9 \%)$ и кашель $(58,9 \%)$, реже встречались одышка $(28,6 \%)$ и боли в грудной клетке при вдохе $(8,9 \%)$. У пяти $(8,9 \%)$ пациентов не было выявлено ни одного легочного симптома, но обнаружены рентгено- логические признаки пневмонии. На рентгенограммах органов грудной клетки наиболее часто встречались локализованные очаги инфильтрации легочной ткани $(35,7 \%$ случаев), несколько реже - двусторонняя или многодолевая инфильтрация (25,0\%). Двусторонняя интерстициальная инфильтрация выявлялась в $12,5 \%$ случаев. У пяти пациентов, в том числе у трех с нокардиозом, обнаружены очаги распада легочной ткани.

Осложнения пневмонии зафиксированы у $26(46,4 \%)$ больных. Наиболее часто отмечалась дыхательная недостаточность, потребовавшая искусственной вентиляции легких, - 15 случаев. Зарегистрированы также острый респираторный дистресс-синдром взрослых (четыре случая) и септический шок (два случая).

Предикторами смерти от пневмонии у пациентов с системной красной волчанкой признаны большая суточная и кумулятивная доза ГКС (в среднем 41,3 $\pm 16,0$ мг/сут и 596,3 $\pm 232,6$ мг), а также высокая активность патологии по MEX-SLEDAI $(8,13 \pm 6,32$ балла) и применение искусственной вентиляции легких. Однако при многофакторном анализе сохранили значимость только применение искусственной вентиляции легких $(\mathrm{p}=0,024)$ и ГКС в дозе $\geq 15$ мг/сут $(\mathrm{p}=0,045)$. Частота летальных исходов составила $26,8 \%$.

Американские исследователи установили, что у больных системной красной волчанкой с повышенным риском развития пневмонии были связаны такие факторы, как мужской пол (ОШ 2,7 (95\% ДИ 0,98$6,80) ; \mathrm{p}=0,03)$, нефрит в анамнезе (ОШ 2,3 (95\% ДИ 1,1-4,7); $\mathrm{p}=0,02)$, лейкопения (ОШ 2,1 (95\% ДИ $1,0-4,4) ; \mathrm{p}=0,04)$, лечение иммуносупрессивными препаратами (циклофосфамидом (ЦФ), азатиоприном, МТ и циклоспорином А) (ОШ 2,7 (95\% ДИ 1,2-6,7); $\mathrm{p}=0,01$ ) и наличие аллеля гена ФНО-альфа238A (ОШ 4,0 (95\% ДИ 1,5-9,8)). Hе обнаружено достоверной ассоциации частоты развития пневмонии с возрастом, продолжительностью болезни, приемом ГКС или гидро- 
ксихлорохина, курением, а также вариациями аллелей MBL2 или FCGR2A [26].

По данным специалистов Научноисследовательского института ревматологии им. В.А. Насоновой, факторами риска развития пневмонии у больных системной красной волчанкой были высокая активность воспалительного процесса (ОШ 11,6 (95\% ДИ 3,2-41,3); $\mathrm{p}<0,001)$, отсутствие лечения цитотоксиками (ОШ 10,5 (95\% ДИ 3,3-43,3); $<<0,001)$ и прием ГКС в дозе > 20 мг/сут (ОШ 11,9 (95\% ДИ 7,3-43,3); $<<0,001)$. Сочетание первого и второго факторов приводило к четырехкратному увеличению риска развития пневмонии (ОШ 48,0; p<0,001) [13].

В ходе многоцентрового исследования EUSTAR показано, что у пациентов с системной склеродермией наиболее частой $(11,1 \%)$ серьезной инфекцией была пневмония, которая стала причиной смерти в $4 \%$ случаев [27]. Развитие пневмонии у таких пациентов могло быть обусловлено не только сниженной вентиляционной способностью легких, но и нарушением функции пищевода с последующей аспирацией содержимого, применением препаратов с выраженным цитотоксическим эффектом (ЦФ, микофенолата мофетила (ММФ), РТМ) [28-30].

В настоящее время иммуносупрессивная терапия позволяет достигнуть ремиссии у $80-85 \%$ больных ANCA-ассоциированными васкулитами (гранулематоз с полиангиитом, микроскопический полиангиит, эозинофильный гранулематоз с полиангиитом, или синдром Черджа - Стросс). В то же время прослеживается ассоциация указанного лечения с нарастанием числа серьезных инфекций. Так, согласно результатам исследования EUVAS, включавшего 524 больных ANCA-ассоциированными васкулитами, инфекции были причиной смерти в $71 \%$ случаев. При этом поражение нижних дыхательных путей - наиболее частым (24\%) ceрьезным инфекционным осложнением. В связи с этим авторы указали на необходимость вакцинации таких больных, в первую очередь против гриппа и пневмококковой инфекции [31].

У 489 пациентов с ANCA-ассоциированными васкулитами частота серьезных коморбидных инфекций через год, три и пять лет наблюдения составила 22, 23 и 26\%. При этом ИНДП были наиболее частым (42\%) осложнением, особенно в течение первых трех месяцев [32].

Анализ госпитальной летальности, выполненный индийскими учеными, свидетельствует, что инфекции были ведущей причиной смерти больных полимиозитом (63,2\% случаев). При этом в перечне инфекционных осложнений первое место занимали пневмонии (54,2\%) [33]. Как следует из вышеизложенного, наряду с пневмококковыми пневмониями у больных ИВРЗ, особенно на фоне активной терапии ГИБП, могут развиваться ИНДП, обусловленные иными, в том числе оппортунистическими, инфекциями.

\section{Пневмоцистоз}

Возбудитель пневмоцисто за - Pneumocystis jirovecii (ранее P. carinii). Это внеклеточный возбудитель с преимущественной тропностью к легочной ткани, который поражает пневмоциты первого и второго порядка. P. jirovecii широко распространен и выделяется повсеместно. Источник инфекции - больной или носитель (до 10\% здоровых лиц). Частота колонизации P. jirovecii у больных ИВРЗ составляет от 11 до 28,5\%. В качестве факторов риска пневмоцистной колонизации фигурируют ИВРЗ (ОР 15,1; p<0,001), возраст старше 60 лет (OP 3,13; $\mathrm{p}=0,015)$, низкое содержание $\mathrm{CD} 4^{+}$ Т-лимфоцитов (ОР 0,9 (95\% ДИ 0,80-0,99)), высокие суточные дозы ГКС (ОР 1,6 (95\% ДИ 1,1-2,3)), терапия ИНФ (ОР 3,6; p <0,003) [34-37]. По данным метаанализа, включавшего 11905 пациентов с ИВРЗ, частота развития пневмоцистной пневмонии у лиц с гранулематозом с полиангиитом составила $12 \%$, полимиозитом - 6\%, системной красной волчанкой - 5\%, РА - $1 \%$. Частота лечения в стационаре по поводу пневмоцистной пневмонии также была максимальной среди больных гранулематозом с полиангиитом - 89 на 10 тыс. госпитализаций в год. Для других ИВРЗ значения рассматриваемого показателя были следующими: узелковый полиартериит - 65, воспалительные миопатии - 27, системная красная волчанка - 12, системная склеродермия - восемь, РА - два [38].

Высокая активность болезни, патология почек, интерстициальный легочный фиброз, большая суточная доза ГКС, лимфопения и низкое количество $\mathrm{CD} 4^{+}$T-клеток рассматриваются как факторы риска развития пневмоцистной пневмонии у больных системной красной волчанкой и полимиозитом. Возникновение пневмоцистной пневмонии у больных РА ассоциируется исключительно с приемом иммуносупрессивных препаратов, включая МТ, иФНО-альфа и ТЦЗ. Описаны также случаи развития пневмоцистной пневмонии у пациентов с гранулематозом с полиангиитом, системной красной волчанкой и РА при лечении РТМ [39-41]. Для пневмоцистной пневмонии характерны острое начало, лихорадка, боль в грудной клетке, нарастающее тахипноэ, сухой непродуктивный кашель при скудности данных физикального исследования. В отсутствие лечения симптоматика быстро прогрессирует вплоть до тяжелой дыхательной недостаточности и летального исхода. При проведении рентгенологического исследования или компьютерной томографии (КТ) органов грудной клетки обнаруживают диффузные билатеральные прикорневые инфильтраты, распространяющиеся от корней легких к периферии. Участки повышенной пневматизации сочетаются с перибронхиальной инфильтрацией (так называемые матовые стекла, ватные легкие, легкие сквозь вуаль и т.д.). Длительное время после перенесенной пневмоцистной пневмонии на рентгенограммах определяется деформированный легочный рисунок за счет пневмофиброза. Наблюдение за динамикой процесса наряду с интерстициальным 
Таблица 1. Рекомендации по профилактике пневмоцистной пневмонии у больных системными ИВРЗ

\begin{tabular}{|c|c|c|c|}
\hline Заболевание & $\begin{array}{l}\text { Необходимость } \\
\text { профилактики }\end{array}$ & Показания для назначения & Особые факторы \\
\hline Гранулематоз с полиангиитом & Необходима & $\begin{array}{l}\text { Все больные в период } \\
\text { индукционной терапии }\end{array}$ & - \\
\hline Системная красная волчанка & $\begin{array}{l}\text { Условно } \\
\text { необходима* }\end{array}$ & Высокие дозы ГКС & $\begin{array}{l}\text { Лимфопения } \\
\text { Низкое количество } \mathrm{CD} 4^{+* * *} \\
\text { Иммуносупрессивные схемы терапии }\end{array}$ \\
\hline Полимиозит & $\begin{array}{l}\text { Условно } \\
\text { необходима }\end{array}$ & Высокие дозы ГКС & $\begin{array}{l}\text { Лимфопения^*} \\
\text { Низкое количество CD } 4^{+* \star \star \star} \\
\text { Тяжелые формы болезни }\end{array}$ \\
\hline $\begin{array}{l}\text { Узелковый полиартериит, } \\
\text { ANCA-ассоциированный васкулит }\end{array}$ & $\begin{array}{l}\text { Условно } \\
\text { необходима }\end{array}$ & $\begin{array}{l}\text { Индукционная терапия } \\
\text { и/или высокие дозы ГКС }\end{array}$ & $\begin{array}{l}\text { Лимфопения }{ }^{* *} \\
\text { Низкое количество } \mathrm{CD} 4^{+* * * *}\end{array}$ \\
\hline Ревматоидный артрит & Не требуется & - & - \\
\hline Гигантоклеточный артериит & Не требуется & - & - \\
\hline Системная склеродермия & Не требуется & - & - \\
\hline
\end{tabular}

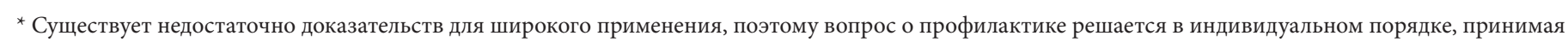
во внимание вышеуказанные особые факторы.

** При уровне лимфоцитов $<500$ клеток/мл.

*** При содержании CD $4^{+}<350$ клеток/мл.

**** При содержании $\mathrm{CD} 4^{+}<200$ клеток/мл.

поражением подтверждает паренхиматозную природу пневмонии. Указанные рентгенологические изменения, равно как и клиническая картина, могут совпадать с таковыми у больных РА с феноменом метотрексатного пневмонита.

Диагноз верифицируют с помощью рентгенологических или КТ-признаков пневмонии в сочетании с выявлением $P$. jirovecii с помощью микроскопии или гистологическом исследовании материала для биопсии или полимеразной цепной реакции.

Неблагоприятными прогностическими факторами у лиц с пневмоцистной пневмонией, развившейся на фоне ИВРЗ, признаны низкие значения сывороточного альбумина и холинэстеразы, сниженный альвеолярно-артериальный градиент по кислороду при оценке газообмена в легких, интратрахеальная интубация и необходимость пребывания в блоке интенсивной терапии.

Показатели госпитальной летальности при пневмоцистной пневмонии в зависимости от фонового ИВРЗ следующие: при гранулематозе с полиангиитом - 62,5\%, воспалительной миопатии - 57,7\%, узелковом полиартериите - 47,6\%, системной красной волчанке - 46,3\%, PA - 30,8\%, системной склеродермии - 16,7\% [33]. Смертность от пневмоцистной пневмонии среди ВИЧ-негативных пациентов втрое превышает таковую среди больных СПИДом - 30-60 и 10-20\% соответственно $[42,43]$.

В связи со сказанным разработка международного консенсуса по профилактике пневмоцистной пневмонии с четким определением показаний и лекарственных схем крайне актуальна [44]. Наиболее надежные данные в поддержку необходимости профилактики пневмоцистной пневмонии получены в отношении больных гранулематозом с полиангиитом.

Эксперты Европейской антиревматической лиги (European League Against Rheumatism - EULAR) поддерживают профилактику заболевания с использованием ко-тримоксазола (800/160 мг через день или 400/80 мг ежедневно) для всех пациентов с ANCA-ассоциированными васкулитами, получающих терапию ЦФ, в отсутствие противопоказаний [45].

В то же время низкая частота пневмоцистной пневмонии в США и Европе среди больных другими ИВРЗ свидетельствует о том, что всеобщая рутинная профилактика данной инфекции неоправданна, а широкое применение с этой целью ко-тримоксазола может изменить соотношение «польза/риск» в сторону второго [46].
В настоящее время опубликованы алгоритмы профилактики пневмоцистной пневмонии ряда групп исследователей [47-49]. В частности, в табл. 1 представлены рекомендации американских авторов, которые предлагают не назначать профилактику пневмоцистной пневмонии больным РА, гигантоклеточным артериитом и системной склеродермией [46].

В то же время в рекомендациях, подготовленных экспертами группы ISMIR, профилактика пневмоцистной пневмонии показана всем больным РА при содержании $\mathrm{CD} 4^{+}$-клеток $<200 /$ мкл или лимфоцитов $<500 /$ мкл с обязательным мониторингом нежелательных реакций терапии. Кроме того, больные РА с тремя и более факторами риска (возраст старше 65 лет, число лимфоцитов $>500 /$ мкл, но $<1500 /$ мкл, прием иммунодепрессантов и/или ГКС более трех месяцев, применение ГИБП в анамнезе, сопутствующие заболевания легких, снижение содержания сывороточного альбумина или иммуноглобулина G) требуют особого внимания и рассматриваются в качестве кандидатов для первичной профилактики пневмоцистной пневмонии в индивидуальном порядке [50].

С учетом результатов крупного наблюдательного исследования [51], в 2018 г. K.Winthrop и J. Baddley 
предложили алгоритм профилактики пневмоцистной пневмонии в зависимости от нозологии, дозы и длительности приема ГКС (табл. 2). Поскольку эти рекомендации основаны на ограниченных данных и мнении экспертов, необходимо проведение дальнейших исследований в данной области [52]. Следует отметить, что все вышеуказанные алгоритмы требуют обсуждения и подлежат доработке по мере накопления данных в области профилактики пневмоцистной пневмонии у больных ИВРЗ.

\section{Цитомегаловирусная инфекция}

Китайские исследователи проанализировали данные 62 больных ИВРЗ с активной цитомегаловирусной инфекцией, включая цитомегаловирусную пневмонию. Последней страдали 14 пациентов. Наиболее частым фоновым заболеванием была системная красная волчанка $(41,9 \%)$, далее по значимости следовали синдром Шегрена $(16,1 \%)$ и системный васкулит (12,9\%). Факторами риска развития цитомегаловирусной инфекции при ИВРЗ были лимфопения, низкое содержание $\mathrm{CD}^{+}{ }^{-}$ лимфоцитов, применение ГКС, ЦФ или ММФ, сочетанное применение двух и более препаратов с иммуносупрессивным действием, тяжелая сопутствующая инфекция [53]. Основной клинический симптом цитомегаловирусной пневмонии, обнаруженный практически у 100\% больных, - сильный приступообразный сухой или малопродуктивный коклюшеподобный кашель.

Одним из ранних и наиболее постоянных признаков заболевания является одышка, которая носит инспираторный или смешанный характер, вначале появляется при физической нагрузке, затем - в покое. Одышка постоянная, умеренная (в отличие от пневмоцистной пневмонии), но значительно возрастающая при минимальной нагрузке.

При цитомегаловирусной инфекции пневмония лишь одно из проявлений генерализованного заболевания. Нередко поражение легких сочетается с патологией других

Таблица 2. Назначение и прекращзение профилактики пневмоцистной пневмонии при лечении ГКС в разных дозах

\begin{tabular}{|c|c|c|c|}
\hline \multirow[t]{2}{*}{ Заболевание } & \multicolumn{3}{|l|}{ Доза ГКС, мг/сут } \\
\hline & $15-30^{*}$ & $>30^{*}$ & $<15$ \\
\hline $\begin{array}{l}\text { Гранулематоз } \\
\text { с полиангиитом }\end{array}$ & $\begin{array}{l}\text { Назначение } \\
\text { профилактики }\end{array}$ & $\begin{array}{l}\text { Назначение } \\
\text { профилактики }\end{array}$ & $\begin{array}{l}\text { Прекращение } \\
\text { профилактики }\end{array}$ \\
\hline $\begin{array}{l}\text { Микроскопический } \\
\text { полиангиит }\end{array}$ & $\begin{array}{l}\text { Назначение } \\
\text { профилактики }\end{array}$ & $\begin{array}{l}\text { Назначение } \\
\text { профилактики }\end{array}$ & $\begin{array}{l}\text { Прекращение } \\
\text { профилактики }\end{array}$ \\
\hline Системная склеродермия & $\begin{array}{l}\text { Назначение } \\
\text { профилактики }\end{array}$ & $\begin{array}{l}\text { Назначение } \\
\text { профилактики }\end{array}$ & $\begin{array}{l}\text { Прекращение } \\
\text { профилактики }\end{array}$ \\
\hline Полимиозит & $\begin{array}{l}\text { Назначение } \\
\text { профилактики }{ }^{\star * *}\end{array}$ & $\begin{array}{l}\text { Назначение } \\
\text { профилактики }\end{array}$ & $\begin{array}{l}\text { Прекращение } \\
\text { профилактики }\end{array}$ \\
\hline Системная красная волчанка & $\begin{array}{l}\text { Профилактика } \\
\text { не требуется }\end{array}$ & $\begin{array}{l}\text { Назначение } \\
\text { профилактики }\end{array}$ & $\begin{array}{l}\text { Прекращение } \\
\text { профилактики }\end{array}$ \\
\hline Ревматоидный артрит & $\begin{array}{l}\text { Профилактика } \\
\text { не требуется }\end{array}$ & $\begin{array}{l}\text { Назначение } \\
\text { профилактики }\end{array}$ & $\begin{array}{l}\text { Прекращение } \\
\text { профилактики }\end{array}$ \\
\hline
\end{tabular}

* Учитывается длительное применение ГКС $\geq 4$ недель.

** При наличии двух дополнительных факторов риска на момент прекращения: исходная лимфопения, низкое количество CD4+, применение ЦФ, иФНО-альфа или РТМ, начальная доза ГКС > 60 мг.

*** При наличии по крайней мере одного дополнительного фактора риска: исходная лимфопения, низкое количество CD4 ${ }^{+}$, применение ЦФ, иФНО-альфа или РТМ, начальная доза ГКС > 60 мг.

органов (энтероколит, эзофагит, гепатит, ретинит, полирадикулопатия). Для цитомегаловирусной пневмонии характерно длительное рецидивирующее течение с постепенным нарастанием тяжести заболевания. При несвоевременной постановке диагноза, непроведении этиотропной терапии, присоединении бактериальной инфекции возможно развитие симптомов дыхательной недостаточности, нарастающего респираторного дистресс-синдрома с высокой вероятностью летального исхода.

При проведении КТ наблюдаются изменение легочной ткани по типу матового стекла, ее уплотнение, утолщение стенок бронхиол или бронхоэктазы, интерстициальная сетчатость без эмфиземы, очаговые и мелкофокусные изменения. Для лечения манифестной цитомегаловирусной инфекции показаны противовирусные препараты ганцикловир, валганцикловир, фоскарнет и цидофовир. Их эффективность доказана в многочисленных исследованиях. Противогерпетические препараты (ацикловир, валацикловир, фамцикловир) малоэффективны в отношении цитомегаловируса, поэтому не должны применяться при манифестной форме заболевания.

\section{Вакцинация}

Антиинфекционные препараты не позволяют решить все проблемы с пневмонией в частности и инфекциями в целом. Выходом из сложившейся ситуации может быть создание, совершенствование и активное использование в клинической практике вакцин.

В ходе многочисленных исследований продемонстрирована иммуногенность и безопасность вакцин против гриппа и пневмококковой инфекции при многих ИВРЗ. Так, в исследовании, выполненном в Научно-исследовательском институте ревматологии им. В.А. Насоновой, продемонстрирована абсолютная клиническая эффективность трехвалентной инактивированной сплит-вакцины против гриппа и положительная иммунная реакция на нее. В исследование было включено 126 лиц. 52 из них - пациенты с ревматоидным артритом, 34 с анкилозирующим спондилитом. Группу контроля составили 40 человек. Среди больных доля ответивших на вакцину составила 70\%, в группе контроля - 75\%. Терапия иФНО-альфа и МТ не оказывала значимого влияния на поствакцинальный ответ. У большинства (77,4\%) обследованных в поствакцинальный период симптомов не отмечено. Локальные реакции 
и общие реакции низкой степени зафиксированы в 15,0 и 7,6\% случаев соответственно. Поствакцинальные реакции характеризовались как типичные, в течение суток исчезали без дополнительных корригирующих мероприятий. За весь период наблюдения случаев обострения ревматоидного артрита или анкилозирующего спондилита либо развития новых клинически значимых аутоиммунных феноменов не зафиксировано [54]. Результаты другой нашей работы свидетельствовали о достаточной иммуногенности, клинической эффективности и хорошей переносимости 23-валентной пневмококковой полисахаридной вакцины у 110 испытуемых, включая 79 больных РА. В течение 24 месяцев наблюдения клинических и рентгенологических симптомов пневмонии не зарегистрировано. Через три месяца после вакцинации у больных РА и в группе контроля отмечено более чем двукратное повышение содержания пневмококковых антител. Несмотря на снижение их концентрации к 12-му месяцу, она сохранялась на должном уровне. К 24-му месяцу таковая значимо повысилась. Во всех случаях течение поствакцинального периода было благоприятным. У 72 (65\%) лиц нежелательные реакции на вакцину отсутствовали. У 38 (35\%) отмечены боль, припухлость и гиперемия кожи до 2 см в месте инъекции, субфебрилитет. Указанные реакции расценены как типичные поствакцинальные. Они не были связаны с проводимой терапией, не требовали изменения схемы лечения РА и регрессировали в течение суток без применения дополнительных мер. Эпизодов обострения РА или возникновения каких-либо новых аутоиммунных расстройств не отмечено [55].

Согласно современным рекомендациям EULAR [56], иммунизация гриппозной и пневмококковой вакцинами показана для большинства больных ИВРЗ, что объясняется высоким риском летальных исходов от инфекций дыхательных путей в данной популяции. Для достижения оптимального иммунного ответа у пациентов с ИВРЗ вакцинацию следует проводить до назначения ГИБП. При необходимости ее можно проводить во время терапии как БПВП, так и ГИБП. Больным ИВРЗ, которым показан РТМ, вакцинация должна проводиться до начала лечения, поскольку препарат ингибирует гуморальный ответ после введения указанных вакцин [57-59]. Если же таковая уже проводится, вакцинация выполняется как минимум через шесть месяцев от начала анти-В-клеточной терапии, но не менее чем за четыре недели до следующего курса.

\section{Заключение}

В современных условиях проблема ИНДП у больных ИВРЗ представляется весьма актуальной. Поэтому необходимо продолжать исследование различных ее аспектов, в том числе эффективности и безопасности вакцинации, в рамках единой научной программы с дальнейшей разработкой клинических рекомендаций по курации этой категории пациентов.

Настоящзая публикация подготовлена в рамках научно-исследовательской работы по теме «Коморбидные инфекиии при ревматических заболеваниях и проблемы безопасности антиревматической терапии» (AAAA-A19-119021190148-3, 0514-2019-0005).

\section{Литература}

1. https://news.ru/russia/vy-rossii-vyrosla-zabolevaemostpnevmoniej/. Дата обращения 18.01.2020.

2. Зайщев A.A. Внебольничная пневмония: «bene dignoscitur, bene curator» // Consilium Medicum. 2017. T. 19. № 3. C. 55-60.

3. Bernatsky S., Hudson M., Suissa S. Anti-rheumatic drug use and risk of serious infections in rheumatoid arthritis // Rheumatology (Oxford). 2007. Vol. 46. № 7. P. 1157-1160.

4. Yun H., Xie F., Delzell E. et al. Comparative risk of hospitalized infection associated with biologic agents in rheumatoid arthritis patients enrolled in medicare // Arthritis Rheumatol. 2016. Vol. 68. № 1. P. 56-66.

5. Mori S., Yoshitama T., Hidaka T. et al. Comparative risk of hospitalized infection between biological agents in rheumatoid arthritis patients: a multicenter retrospective cohort study in Japan // PLoS One. 2017. Vol. 12. № 6. P. e0179179.

6. Smitten A.L., Choi H.K., Hochberg M.C. et al. The risk of hospitalized infection in patients with rheumatoid arthritis // J. Rheumatol. 2008. Vol. 35. № 3. P. 387-393.

7. Wotton C.J., Goldacre M.J. Risk of invasive pneumococcal disease in people admitted to hospital with selected immunemediated diseases: record linkage cohort analyses // J. Epidemiol. Community Health. 2012. Vol. 66. № 12. P. 1177-1181.
8. Koivuniemi R., Leirisalo-Repo M., Suomalainen R. et al. Infectious causes of death in patients with rheumatoid arthritis: an autopsy study // Scand. J. Rheumatol. 2006. Vol. 35. № 4. P. 273-276.

9. Wolfe F., Mitchell D.M., Sibley J.T. et al. The mortality of rheumatoid arthritis // Arthritis Rheum. 1994. Vol. 37. № 4. P. 481-494.

10. Yazici Y., Curtis J.R., Ince A. et al. Efficacy of tocilizumab in patients with moderate to severe active rheumatoid arthritis and a previous inadequate response to disease-modifying antirheumatic drugs: the ROSE study // Ann. Rheum. Dis. 2012. Vol. 71. № 2. P. 198-205.

11. Yoo H.G., Yu H.M., Jun J.B. et al. Risk factors of severe infections in patients with rheumatoid arthritis treated with leflunomide // Mod. Rheumatol. 2013. Vol. 23. № 4. P. 709-715.

12. Wolfe F., Caplan L., Michaud K. Treatment for rheumatoid arthritis and the risk of hospitalization for pneumonia: associations with prednisone, disease-modifying antirheumatic drugs, and anti-tumor necrosis factor therapy // Arthritis Rheum. 2006. Vol. 54. № 2. P. 628-634.

13. Полянская М.В. Пневмония у пациентов с ревматическими заболеваниями: частота встречаемости, клиническая картина, факторы риска: автореф. дис. ... канд. мед. наук. М., 2009.

14. Coyne P., Hamilton J., Heycock C. et al. Acute lower respiratory tract infections in patients with rheumatoid arthritis // J. Rheumatol. 2007. Vol. 34. № 9. P. 1832-1836. 
15. Zamora-Legoff J.A., Krause M.L., Crowson C.S. et al. Risk of serious infection in patients with rheumatoid arthritisassociated interstitial lung disease // Clin. Rheumatol. 2016. Vol. 35. № 10. P. 2585-2589.

16. Takayanagi N. Biological agents and respiratory infections: causative mechanisms and practice management // Respir. Investig. 2015. Vol. 53. № 5. P. 185-200.

17. Listing J., Strangfeld A., Kary S. et al. Infections in patients with rheumatoid arthritis treated with biologic agents // Arthritis Rheum. 2005. Vol. 52. № 11. P. 3403-3412.

18. Salliot C., Gossec L., Ruyssen-Witrand A. et al. Infections during tumour necrosis factor-alpha blocker therapy for rheumatic diseases in daily practice: a systematic retrospective study of 709 patients // Rheumatology (Oxford). 2007. Vol. 46. № 2. P. 327-334.

19. Pérez-Sola M.J., Torre-Cisneros J., Pérez-Zafrilla B. et al. Infections in patients treated with tumor necrosis factor antagonists: incidence, etiology and mortality in the BIOBADASER registry // Med. Clin. (Barc.). 2011. Vol. 137. № 12. P. 533-540.

20. Lane M.A., McDonald J.R., Zeringue A.L. et al. TNF-a antagonist use and risk of hospitalization for infection in a national cohort of veterans with rheumatoid arthritis // Medicine (Baltimore). 2011. Vol. 90. № 2. P. 139-145.

21. Van Vollenhoven R.F., Emery P., Bingham C.O. et al. Long-term safety of rituximab in rheumatoid arthritis: 9.5-year follow-up of the global clinical trial programme with a focus on adverse events of interest in RA patients // Ann. Rheum. Dis. 2013. Vol. 72. № 9. P. 1496-1502.

22. Hoshi D., Nakajima A., Inoue E. et al. Incidence of serious respiratory infections in patients with rheumatoid arthritis treated with tocilizumab // Mod. Rheumatol. 2012. Vol. 22. № 1. P. 122-127.

23. Fujiwara H., Nishimoto N., Hamano Y. et al. Masked early symptoms of pneumonia in patients with rheumatoid arthritis during tocilizumab treatment: a report of two cases // Mod. Rheumatol. 2009. Vol. 19. № 1. P. 64-68.

24. Franklin J., Lunt M., Bunn D. et al. Risk and predictors of infection leading to hospitalisation in a large primary-carederived cohort of patients with inflammatory polyarthritis // Ann. Rheum. Dis. 2007. Vol. 66. № 3. P. 308-312.

25. Narata R., Wangkaew S., Kasitanon N., Louthrenoo W. Community-acquired pneumonia in Thai patients with systemic lupus erythematosus // Southeast Asian J. Trop. Med. Public. Health. 2007. Vol. 38. № 3. P. 528-536.

26. Kinder B.W., Freemer M.M., King T.E. Jr. et al. Clinical and genetic risk factors for pneumonia in systemic lupus erythematosus // Arthritis Rheum. 2007. Vol. 56. № 8 P. 2679-2686.

27. Elhai M., Meune C., Boubaya M. et al. Mapping and predicting mortality from systemic sclerosis // Ann. Rheum. Dis. 2017. Vol. 76. № 11. P. 1897-1905.

28. Jordan S., Distler J.H., Maurer B. et al. Effects and safety of rituximab in systemic sclerosis: an analysis from the European Scleroderma Trial and Research (EUSTAR) group // Ann. Rheum. Dis. 2015. Vol. 74. № 6. P. 1188-1194.
29. Poormoghim H., Moradi Lakeh M., Mohammadipour M. et al. Cyclophosphamide for scleroderma lung disease: a systematic review and meta-analysis // Rheumatol. Int. 2012. Vol. 32. № 8. P. 2431-2444.

30. Omair M.A., Alahmadi A., Johnson S.R. Safety and effectiveness of mycophenolate in systemic sclerosis. A systematic review // PLoS One. 2015. Vol. 10. № 5. P. e0124205.

31. Little M.A., Nightingale P., Verburgh C.A. et al. Early mortality in systemic vasculitis: relative contribution of adverse events and active vasculitis // Ann. Rheum. Dis. 2010. Vol. 69. № 6. P. 1036-1043.

32. McGregor J.G., Negrete-Lopez R., Poulton C.J. et al. Adverse events and infectious burden, microbes and temporal outline from immunosuppressive therapy in antineutrophil cytoplasmic antibodyassociated vasculitis with native renal function // Nephrol. Dial. Transplant. 2015. Vol. 30. Suppl. 1. P. i171-181.

33. Muhammed H., Gupta L., Zanwar A.A. et al. Infections are leading cause of in-hospital mortality in indian patients with inflammatory myopathy // J. Clin. Rheumatol. 2019.

34. Mori S., Sugimoto M. Pneumocystis jirovecii infection: an emerging threat to patients with rheumatoid arthritis // Rheumatology (Oxford). 2012. Vol. 51. № 12. P. 2120-2130.

35. Wissmann G., Morilla R., Martín-Garrido I. et al. Pneumocystis jirovecii colonization in patients treated with infliximab // Eur. J. Clin. Invest. 2011. Vol. 41. № 3. P. 343-348.

36. Mekinian A., Durand-Joly I., Hatron P.Y. et al. Pneumocystis jirovecii colonization in patients with systemic autoimmune diseases: prevalence, risk factors of colonization and outcome // Rheumatology (Oxford). 2011. Vol. 50. № 3. P. 569-577.

37. Fritzsche C., Riebold D., Munk-Hartig A. et al. High prevalence of Pneumocystis jirovecii colonization among patients with autoimmune inflammatory diseases and corticosteroid therapy // Scand. J. Rheumatol. 2012. Vol. 41. № 3. P. 208-213.

38. Ward M.M., Donald F. Pneumocystis carinii pneumonia in patients with connective tissue diseases: the role of hospital experience in diagnosis and mortality // Arthritis Rheum. 1999. Vol. 42. № 4. P. 780-789.

39. Hugle B., Solomon M., Harvey E. et al. Pneumocystis jiroveci pneumonia following rituximab treatment in Wegener's granulomatosis // Arthritis Care Res. (Hoboken). 2010. Vol. 62. № 11. P. 1661-1664.

40. Teichmann L.L., Woenckhaus M., Vogel C. et al. Fatal Pneumocystis pneumonia following rituximab administration for rheumatoid arthritis // Rheumatology (Oxford). 2008. Vol. 47. № 8. P. 1256-1257.

41. Tsai M.J., Chou C.W., Lin F.C., Chang S.C. Pneumocystis jiroveci pneumonia in patients with systemic lupus erythematosus after rituximab therapy // Lupus. 2012. Vol. 21. № 8. P. 914-918.

42. Sepkowitz K.A. Opportunistic infections in patients with and patients without acquired immunodeficiency 
syndrome // Clin. Infect. Dis. 2002. Vol. 34. № 8. P. 1098-1107.

43. Gerrard J.G. Pneumocystis carinii pneumonia in HIVnegative immunocompromised adults // Med. J. Aust. 1995. Vol. 162. № 5. P. 233-235.

44. Stamp L.K., Hurst M. Is there a role for consensus guidelines for $\mathrm{P}$. jiroveci pneumonia prophylaxis in immunosuppressed patients with rheumatic diseases? // J. Rheumatol. 2010. Vol. 37. № 4. P. 686-688.

45. Yates M., Watts R.A., Bajema I.M. et al. EULAR/ ERA-EDTA recommendations for the management of ANCA-associated vasculitis // Ann. Rheum. Dis. 2016. Vol. 75. № 9. P. 1583-1594.

46. Wolfe R.M., Peacock J.E. Jr. Pneumocystis pneumonia and the rheumatologist: which patients are at risk and how can PCP be prevented? // Curr. Rheumatol. Rep. 2017. Vol. 19. № 6. P. 35.

47. Sowden E., Carmichael A.J. Autoimmune inflammatory disorders, systemic corticosteroids and pneumocystis pneumonia: a strategy for prevention // BMC Infect. Dis. 2004. Vol. 4. ID 42.

48. Zhang Y., Zheng Y. Pneumocystis jirovecii pneumonia in mycophenolate mofetil-treated patients with connective tissue disease: analysis of 17 cases // Rheumatol. Int. 2014. Vol. 34. № 12. P. 1765-1771.

49. Demoruelle M.K., Kahr A., Verilhac K. et al. Recent-onset systemic lupus erythematosus complicated by acute respiratory failure // Arthritis Care Res. 2013. Vol. 65. № 2. P. 314-323.

50. Galli M., Antinori S., Atzeni F. et al. Recommendations for the management of pulmonary fungal infections in patients with rheumatoid arthritis // Clin Exp. Rheumatol. 2017. Vol. 35. № 6. P. 1018-1028.

51. Park J.W., Curtis J.R., Moon J. et al. Prophylactic effect of trimethoprim-sulfamethoxazole for pneumocystis pneumonia in patients with rheumatic diseases exposed to prolonged high-dose glucocorticoids // Ann. Rheum. Dis. 2018. Vol. 77. № 5. P. 644-649.
52. Winthrop K.L., Baddley J.W. Pneumocystis and glucocorticoid use: to prophylax or not to prophylax (and when?); that is the question // Ann. Rheum. Dis. 2018. Vol. 77. № 5. P. 631-633.

53. Ren L.M., Li Y., Zhang C.F. et al. Clinical characteristics and associated risk factors of cytomegalovirus infection in patients with underlying systemic rheumatic diseases // Zhonghua Yi Xue Za Zhi. 2016. Vol. 96. № 35. P. 2772-2776.

54. Bukhanova D., Belov B., Tarasova G. et al. Assessment of efficacy, safety and immunogenicity of a trivalent split-virus influenza vaccine in patients with rheumatic diseases // Ann. Rheum. Dis. 2019. Vol. 78. Suppl. 2. P. 676.

55. Наумиева М.С., Белов Б.С., Александрова Е.Н. и др. Иммуногенность и безопасность 23-валентной полисахаридной пневмококковой вакцины у больных ревматоидным артритом: результаты двухлетнего наблюдения // Научно-практическая ревматология. 2016. T. 54. № 6. P. 674-680.

56. Furer V., Rondaan C., Heijstek M.W. et al. 2019 update of EULAR recommendations for vaccination in adult patients with autoimmune inflammatory rheumatic diseases // Ann. Rheum. Dis. 2020. Vol. 79. № 1. P. 39-52.

57. Van Assen S., Holvast A., Benne C.A. et al. Humoral responses after influenza vaccination are severely reduced in patients with rheumatoid arthritis treated with rituximab // Arthritis Rheum. 2010. Vol. 62. № 1. P. $75-81$.

58. Bingham C.O., Looney R.J., Deodhar A. et al. Immunization responses in rheumatoid arthritis patients treated with rituximab: results from a controlled clinical trial // Arthritis Rheum. 2010. Vol. 62. № 1. P. 64-74.

59. Crnkic Kapetanovic M., Saxne T., Jönsson G. et al. Rituximab and abatacept but not tocilizumab impair antibody response to pneumococcal conjugate vaccine in patients with rheumatoid arthritis // Arthritis Res. Ther. 2013. Vol. 15. № 5. P. R171.

\title{
The Problem of Lower Respiratory Tract Infections in Rheumatology: Relevance and Ways of Solution
}

\author{
B.S. Belov, MD, PhD, D.V. Bukhanova, G.M. Tarasova, PhD, N.V. Muravyova, PhD \\ V.A. Nasonova Research Institute of Rheumatology
}

Contact person: Boris S. Belov, belovbor@yandex.ru

Infections of lower respiratory tract are prevalent among patients with immune-mediated inflammatory rheumatic diseases (IMIRD). Pneumococcus (Streptococcus pneumoniae) is still considered to be the most real causative agent of pneumonia in both the general population and the ISRD population.

The article presents the frequency and risk factors for developing pneumonia in different IMIRD. Presented the main clinical characteristics, approaches to the treatment and prevention of pathology in the framework of pneumocystic and cytomegalovirus infections. Stressed the importance of flu and pneumococcal infection vaccination in patients with IMIRD.

Key words: rheumatic diseases, lower respiratory tract infections, pneumonia, clinical manifestations, treatment, prevention 


\section{ПНЕВМОВАҚС'23}

(Вакцина пневмококковая, поливалентная)

\section{ПНЕВМОВАКС ${ }^{\circledR 23}$ обеспечивает защиту} от различных проявлений пневмококковой инфекции у взрослых пациентов из групп риска*

- ПНЕВМОВАКС ${ }^{\circledR} 23$ содержит 23 серотипа Streptococcus pneumoniae, что составляет $\approx 90 \%$ серотипов, ответственных за инвазивные пневмококковые инфекции*

- Лицам, подлежащим призыву на военную службу, рекомендована 1 доза полисахаридной 23-валентной вакцины (не позднее, чем за 1 месяц до поступления в воинский коллектив) $)^{* \star}$

- Пациентам до 65 лет с хроническими заболеваниями (включая хронические болезни легких, сердца, сахарный диабет) рекомендуется однократная вакцинация полисахаридной пневмококковой 23-валентной вакциной ${ }^{* *}$

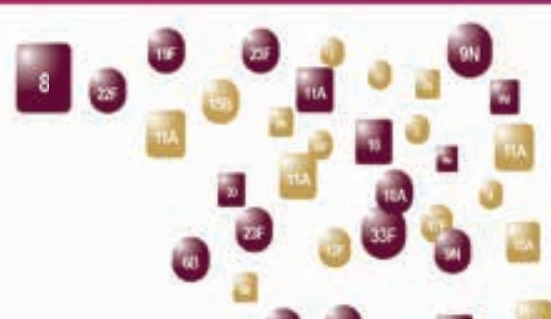
(1) 